\title{
High-Temperature Oxidation of Pure Fe and the Ferritic Steel 2.25Cr1Mo
}

\author{
Vicente Braz Trindade ${ }^{\text {a*, Rodrigo Borin }}{ }^{\mathrm{b}}$, Behzad Zandi Hanjari, \\ Songlan Yang a Ulrich Krupp ${ }^{\text {a }, H a n s-J u ̈ r g e n ~ C h r i s t ~}{ }^{\mathrm{a}}$ \\ anstitut für Werkstofftechnik, Universität Siegen, Germany \\ ${ }^{\mathrm{b}}$ Departamento de Engenharia Mecânica, \\ Universidade Federal de Santa Catarina - SC, Brazil
}

Received: July 19, 2004; Revised: June 21, 2005

\begin{abstract}
The global pressure for recycling and ecological energy production increases steadily in combination with the demand of cost-effective application of materials. However, some severe corrosion problems, associated with the high internal/intergranular corrosion rates in boiler components need to be avoid. Some commercial boiler materials contain a $\mathrm{Cr}$ content of 0.55 (wt. (\%)) - 2.25 (wt. (\%)). This $\mathrm{Cr}$ concentration in the alloys is not sufficient for the formation of a complete dense $\mathrm{Cr}_{2} \mathrm{O}_{3}$ scale. Hence, high oxidation kinetics may result. In this study, pure $\mathrm{Fe}$ and the steel $2.25 \mathrm{Cr} 1 \mathrm{Mo}$ were oxidized in laboratory air at $550{ }^{\circ} \mathrm{C}$ using a thermobalance system. The surface as well as the cross section of oxidized specimens were analysed using scanning electron microscopy in order to quantify several factors (e.g. surface finishing, cold working and grain size) on the overall oxidation kinetics. For alloys with low $\mathrm{Cr}$ content, a decreasing in the grain size leads to an acceleration of the oxidation rate by facilitating the oxygen diffusion along alloy grain boundaries leading to an inward oxide layer formation. The study of effects of surface finish and cold working yielded results revealing that the oxidation process is complex and comparison of results from different laboratories is difficult and should be done.
\end{abstract}

Keywords: low-alloy steels, effect of cold work, effect of grain size, high-temperature oxidation

\section{Introduction}

Low-alloy steels are used for non-heated exit areas in superheater tubes and reheater tubes as part of boiler components. The external surface of these tubes are exposed to air at temperatures between $500{ }^{\circ} \mathrm{C}-600{ }^{\circ} \mathrm{C}$, which leads to a thickness loss of the tubes as a consequence of oxide formation. Inspite of numerous investigations regarding the oxidation of iron-alloys, some questions concerning the oxidation mechanisms remain open. Some studies reported that oxides on low-alloy steels grow mainly by outward Fe diffusion ${ }^{1-3}$, because the diffusion coefficient of Fe in iron oxides is much higher than that of oxygen ${ }^{4-6}$. Even with lower diffusivity of oxygen within the bulk oxide, some investigations ${ }^{7-10}$ pointed out that inward oxidation may take place due to fast oxygen diffusion along grain boundaries of oxides. Others studies ${ }^{11-14}$ proposed the possibility of molecular oxygen permeation through microcracks and/or pores within the oxide scale, which leads to inward oxide growth.

Experimental observations give evidence that inward oxidation occurs on low-alloy steels in the temperature range between $500-600{ }^{\circ} \mathrm{C}$. Figure 1a shows the cross-section of an oxide scale formed on a low-alloy steel exposed to laboratory air at $550{ }^{\circ} \mathrm{C}$ for 72 hours. The position of the original metal surface is represented by a gold marker, which was deposited on the sample surface prior to exposure.

From the calculated Fe-Cr-O phase diagram (Figure 1b) it is possible to predict the phases formed at different temperatures and chemical compositions. At $550{ }^{\circ} \mathrm{C}$, in the region of higher oxygen potential the oxides formed are hematite $\left(\mathrm{Fe}_{2} \mathrm{O}_{3}\right)$ and chromia $\left(\mathrm{Cr}_{2} \mathrm{O}_{3}\right)$. For lower oxygen potentials magnetite $\left(\mathrm{Fe}_{3} \mathrm{O}_{4}\right)$ and spinel
$\left(\mathrm{FeCr}_{2} \mathrm{O}_{4}\right)$ are formed. Wustite $(\mathrm{FeO})$ is not expected, since it is not stable at temperatures below $570{ }^{\circ} \mathrm{C}$. Generally, the scale consists of a coarse-grained outer scale $\left(\mathrm{Fe}_{2} \mathrm{O}_{3}+\mathrm{Fe}_{3} \mathrm{O}_{4}\right)$, growing by outward iron diffusion, and a fine-grained porous inner scale, growing by inward oxygen diffusion $\left(\mathrm{Fe}_{3} \mathrm{O}_{4}+\mathrm{FeCr}_{2} \mathrm{O}_{4}\right)$.

Due to the fact that grain boundaries can serve as high-diffusivity paths for reactive elements in polycrystalline materials, the grain size of the substrate should play an important role on the diffusion controlled oxidation behaviour of low-alloy steels.

The main objectives of the present study are to understand and quantify the effect of the grain size of the substrate on the oxidation behaviour of pure iron and a low-alloy ferritic steel, and to investigate the effect of cold working and surface preparation on the oxidation kinetics of low-alloy steels.

\section{Materials and Experimental Procedure}

Pure $\mathrm{Fe}$ and the commercial steel 2.25Cr1Mo was used. The chemical composition of this steel is given in Table 1 .

The grain size was modified by applying a heat treatment at $1050{ }^{\circ} \mathrm{C}$ in inert gas atmosphere for 2 hours and 112 hours (see Figure 2a). The microstructure of the steel 2.25Cr1Mo consists basically of ferrite. Carbides are also present, but the amount is limited due to the low carbon content. The grain size was measured using the mean linear intercept technique.

In order to investigate the effect of cold working on the oxidation behavior of the low-alloy steel $2.25 \mathrm{Cr} 1 \mathrm{Mo}$, different rolling steps 


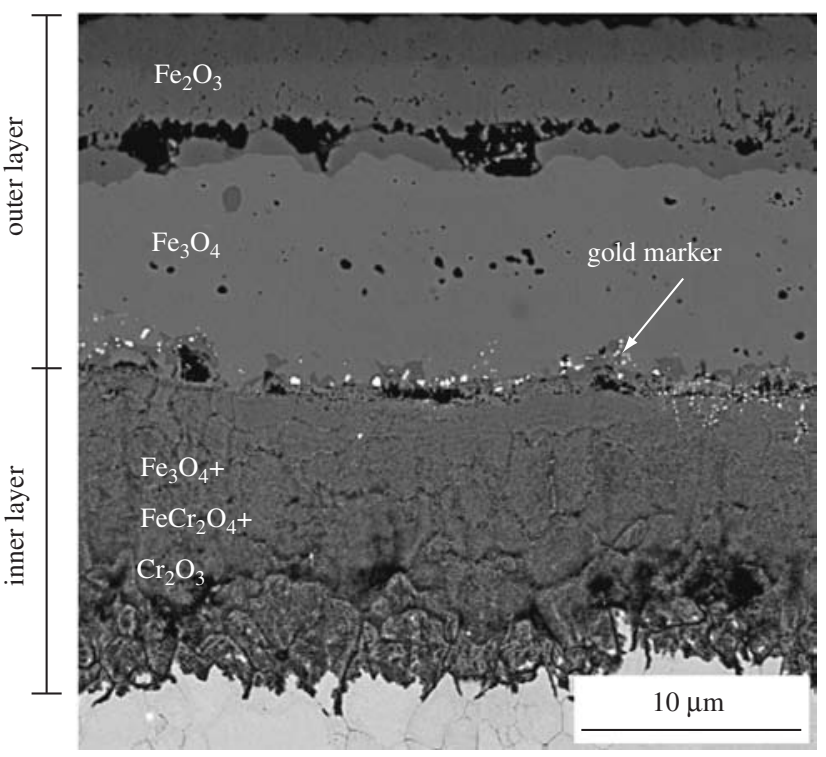

(a)

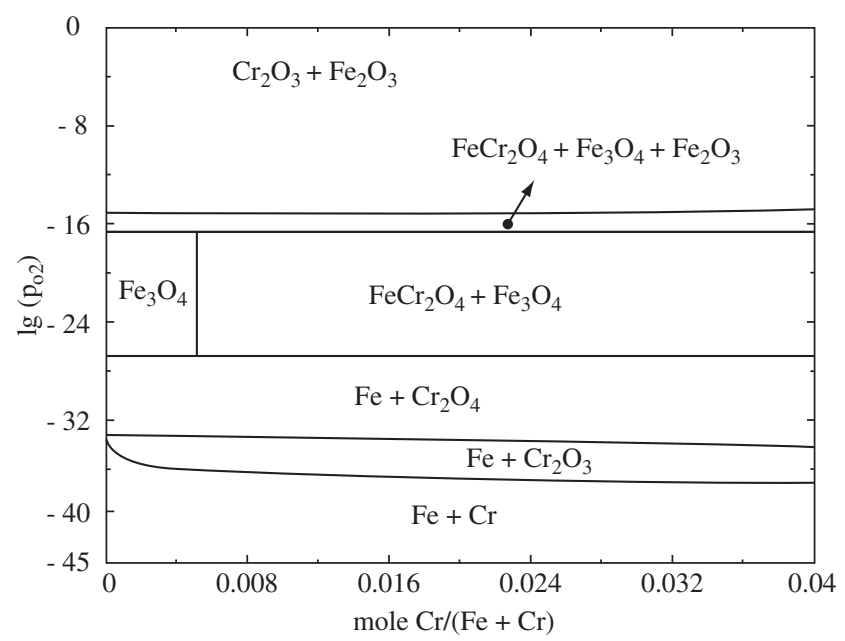

(b)

Figure 1. a) Oxide scale formed on the low-alloy steel $2.25 \mathrm{Cr} 1 \mathrm{Mo}$ after exposure to laboratory air at $550{ }^{\circ} \mathrm{C}$ for 72 hours; and b) influence of low $\mathrm{Cr}$ compositions on the oxide phase stabilities in the $\mathrm{Fe}-\mathrm{Cr}-\mathrm{O}_{2}$ system at $550{ }^{\circ} \mathrm{C}$.

Table 1. Nominal chemical composition (in wt. (\%)) of the $2.25 \mathrm{Cr} 1 \mathrm{Mo}$ low-alloy steel.

\begin{tabular}{cccccccc}
\hline Material & $\mathrm{C}$ & $\mathrm{Cr}$ & $\mathrm{Si}$ & $\mathrm{Ni}$ & $\mathrm{Mn}$ & $\mathrm{Mo}$ & $\mathrm{Fe}$ \\
\hline $2.25 \mathrm{Cr} 1 \mathrm{Mo}$ & 0.09 & 2.25 & 0.23 & 0.44 & 0.59 & 0.96 & bal. \\
\hline
\end{tabular}

were performed in an annealed specimen. Four cold working states were studied (4\%, 12\%, 20\% and 70\%). Typical optical microstructures of the three conditions are presented in Figure $2 b$.

Samples with dimensions $(10 \times 10 \times 3) \mathrm{mm}^{3}$ were used for thermogravimetric study. The samples were ground using $\mathrm{SiC}$ paper down to 1200 grid. They were finally cleaned ultrasonically in ethanol prior to oxidation. Hole of $1 \mathrm{~mm}$ diameter serve for hanging the samples in a thermobalance by means of a quartz thread. Isothermal and thermal cycling thermogravimetry were carried out using a microbalance with a sensibility of $10^{-5} \mathrm{~g}$ in combination with an alumina chamber and a $\mathrm{SiC}$ furnace. After oxidation the specimens were embedded in epoxy and carefully polished using diamond paste down to $1 \mu \mathrm{m}$ and cleaned ultrasonically in ethanol. Analysis of the oxide structure and thickness measurements of oxide layers were performed using scanning electron microscopy (SEM) in combination with energy-dispersive $\mathrm{X}$-ray spectroscopy (EDX) and X-ray diffraction (XRD).

\section{Results and Discussion}

The uneven metal/oxide interface and the preferentially-oxidized grain boundaries in the bulk indicate an internal/intergranular oxidation mechanism by which the scale grows inward (Figure 3). EDS element mappings revealed a gradual increase in the $\mathrm{Cr}$ concentration within the inner scale towards the metal interface. Internal oxides along the substrate grain boundaries consists predominantly of Cr-rich oxides $\left(\mathrm{FeCr}_{2} \mathrm{O}_{4}\right.$ and $\left.\mathrm{Cr}_{2} \mathrm{O}_{3}\right)$.

The parabolic rate constant $\left(k_{\mathrm{p}}\right)$ was calculated from thermogravimetrically measurements using Equation 1.

$$
\left(\frac{\Delta m}{A}\right)^{2}=k_{\mathrm{p}} \mathrm{t}
$$

As shown in Figure 4a the oxidation kinetics decreases strongly as the grain size of the substrate increases. The decrease in the oxidation kinetics can be attributed to the reduction of the inner oxide layer growth kinetics. For the steel $2.25 \mathrm{Cr} 1 \mathrm{Mo}$ the thickness of the inner scale changes considerably as the grain size of the substrate changes from $4 \mu \mathrm{m}$ to $74 \mu \mathrm{m}$ after 72 hours of oxidation in laboratory air at $550{ }^{\circ} \mathrm{C}$. Measurements of the total scale thickness revealed a very small change in the thickness of the outer layer.

Figure $4 \mathrm{~b}$ shows the effect of cold working on the oxidation kinetics of $2.25 \mathrm{Cr} 1 \mathrm{Mo}$ after oxidation in laboratory air at $550{ }^{\circ} \mathrm{C}$ for 24 hours. The oxidation kinetics decreases obviously with increasing degree of cold working. Cold working increases the dislocation density and therefore increases the amount of fast diffusion paths (dislocation pipe) in the sample ${ }^{15}$. Consequently, fast diffusion of chromium to the inner scale can be expected. It was shown ${ }^{16}$ that the increase of chromium concentration in the spinel phase decreases the diffusion coefficient of iron and oxygen in this spinel phase considerably, and therefore reduces the growth kinetics of the outer and the inner oxide layer.

For samples submitted to cold working higher than $42 \%$, recrystallization took place, which causes a reduction in the dislocation density and the formation of very small new grains giving rise to a high inward transport of oxygen into the substrate and therefore higher oxidation kinetics was observed.

Under thermal cycling oxidation conditions, the oxidation kinetics of the steel $2.25 \mathrm{Cr} 1 \mathrm{Mo}$ are dramatically accelerated as shown in Figure 5a. No spallation was observed as usually occurs for NiCrAl alloys. The formation of the inner oxide scale and the preferential oxidation along grain boundaries (see Figure 3) probably works as a pegging, increasing the oxide scale adherence. However, the formed oxide scales have a high tendency of cracking during cooling permitting easy access of oxygen to the substrate/oxide interface leading to higher oxidation kinetics during the next hot cycle.

In order to check, whether the substrate grain size also influence the oxidation behaviour of pure iron, samples were heat-treated to establish two grain sizes and then oxidized in laboratory air at $550{ }^{\circ} \mathrm{C}$ for 72 hours. The gold marker technique was also used in order to define the mass transport direction. The gold marker particles were found in the formed oxide scale revealing that the oxide scale in pure iron also grows by outward Fe diffusion and inward oxygen diffusion. Figure 6a shows that the oxidation kinetics of pure iron also decreases if the grain size of the substrate increases. The oxides formed on pure 
iron at $550{ }^{\circ} \mathrm{C}$ are those expected by the thermodynamic calculation (i.e. $\mathrm{Fe}_{3} \mathrm{O}_{4}$ in contact with the substrate and $\mathrm{Fe}_{2} \mathrm{O}_{3}$ in the outer region). Figure $6 \mathrm{~b}$ shows a scanning electron micrograph of the two layers on the sample surface.

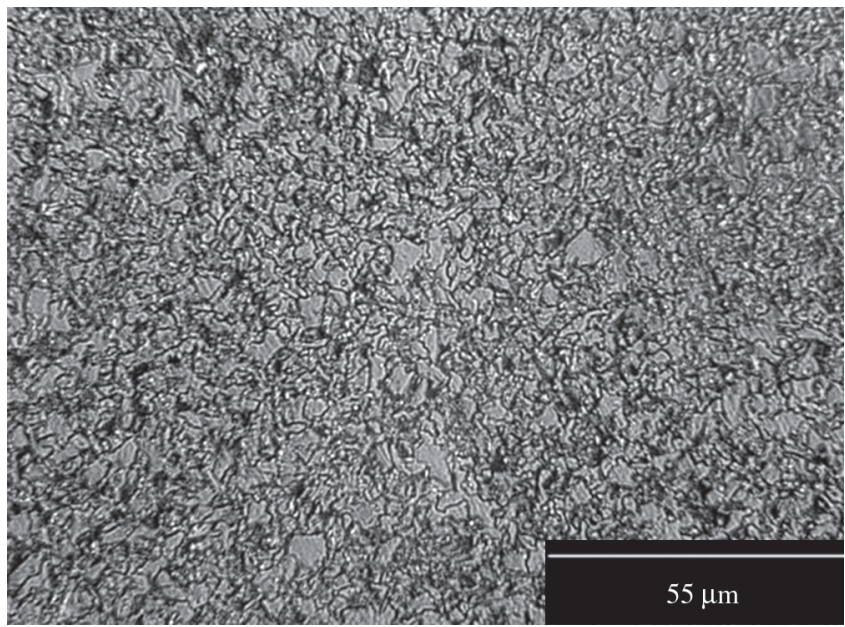

grain size $=4 \mu \mathrm{m}$

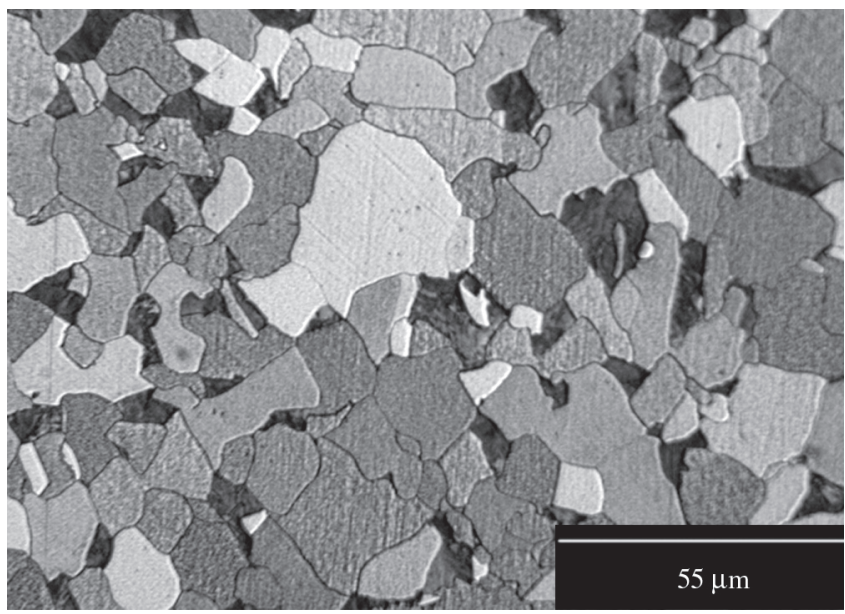

grain size $=13 \mu \mathrm{m}$

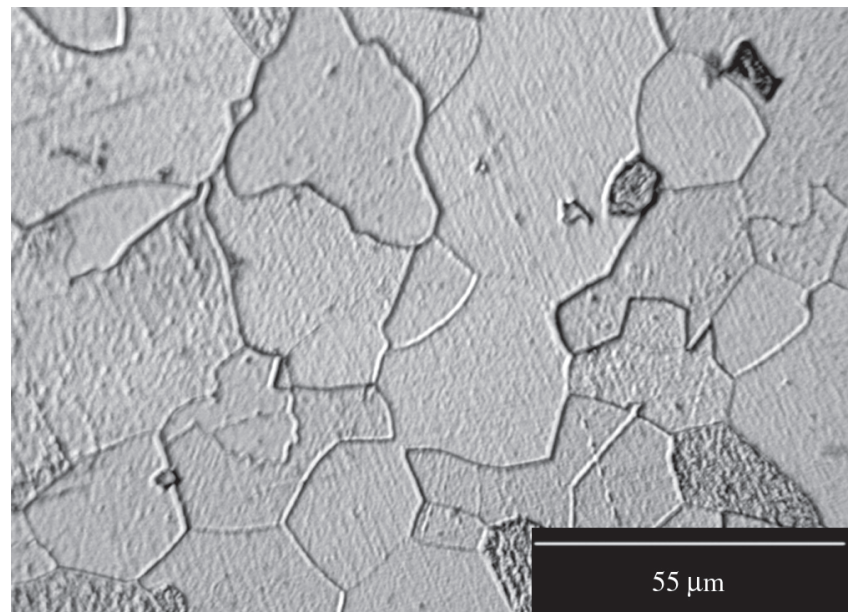

grain size $=24 \mu \mathrm{m}$

(a)
The effect of cold working on pure iron was not investigated in this study. However, intensive investigations were carried out by Caplan et al. ${ }^{17}$. In this investigation it was found that the increase of the degree of cold working led to a increase in the oxidation kinetics. It was assumed that as iron diffuses outwards, vacancies diffuse inwards and the condensation of these vacancies leads to pore formation in the metal/oxide interface. As a consequence, less iron can

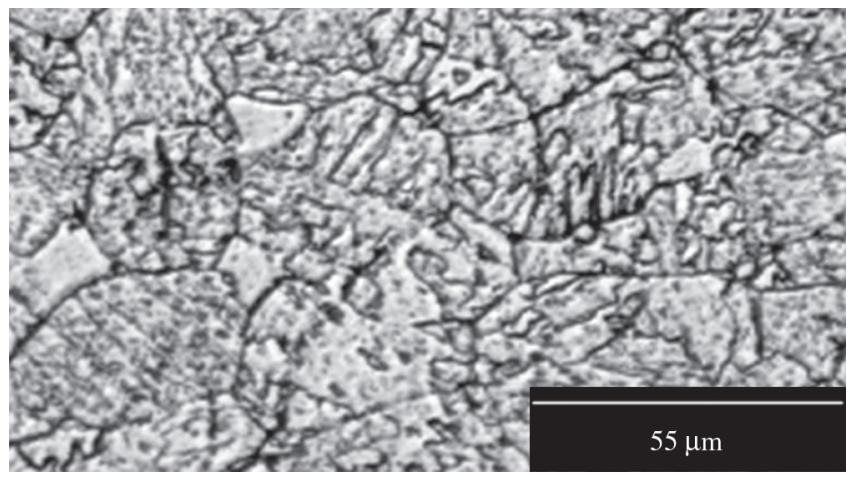

$4 \%$

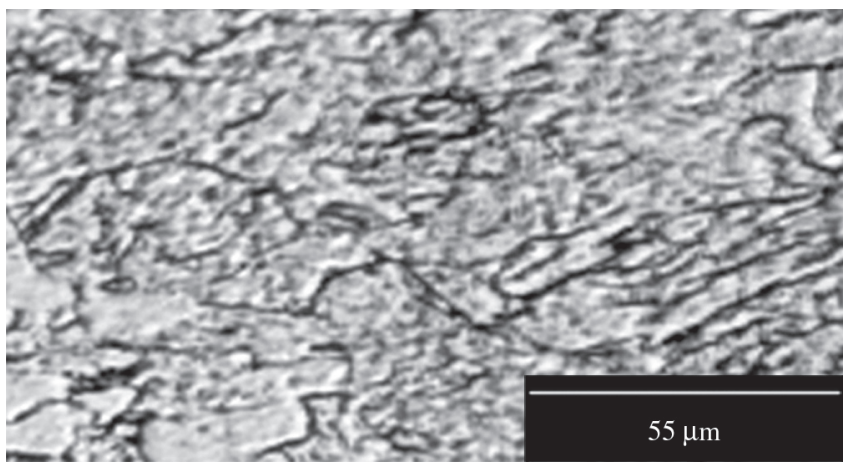

$20 \%$

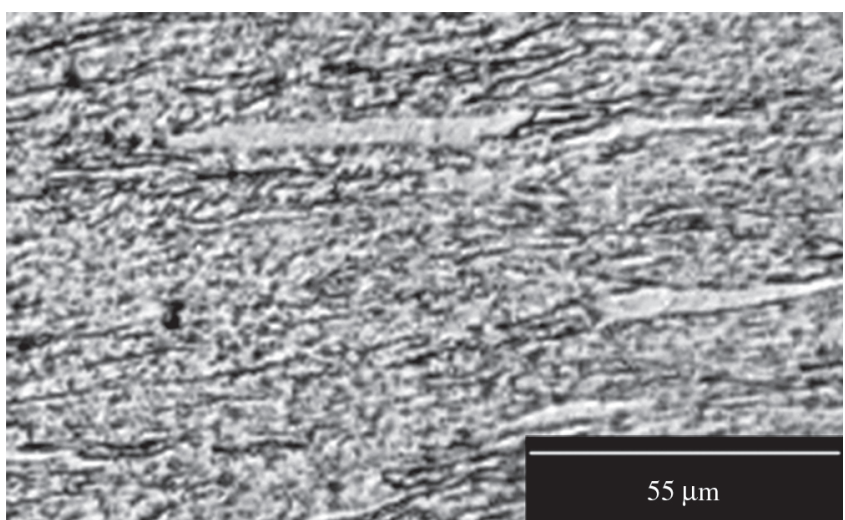

$70 \%$

(b)

Figure 2. Optical microscopy observation of the microstructure of the $2.25 \mathrm{Cr} 1 \mathrm{Mo}$ before oxidation; a) after annealing in inert atmosphere; and b) after cold working. 


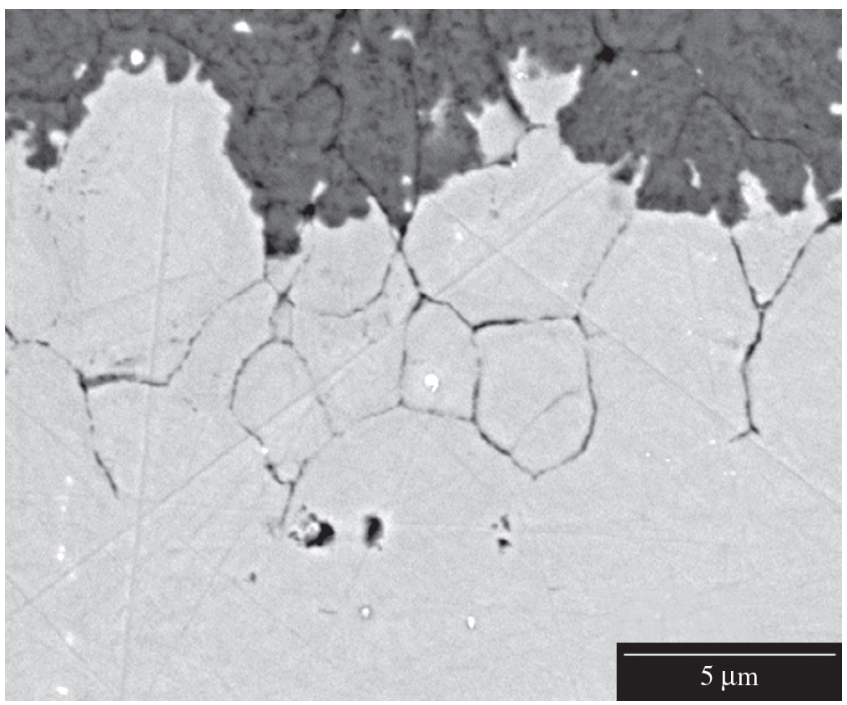

Figure 3. Intergranular oxidation in $2.25 \mathrm{Cr} 1 \mathrm{Mo}$ steel with grain size of $4 \mu \mathrm{m}$ after exposure to laboratory air for 72 hours at $550{ }^{\circ} \mathrm{C}$.

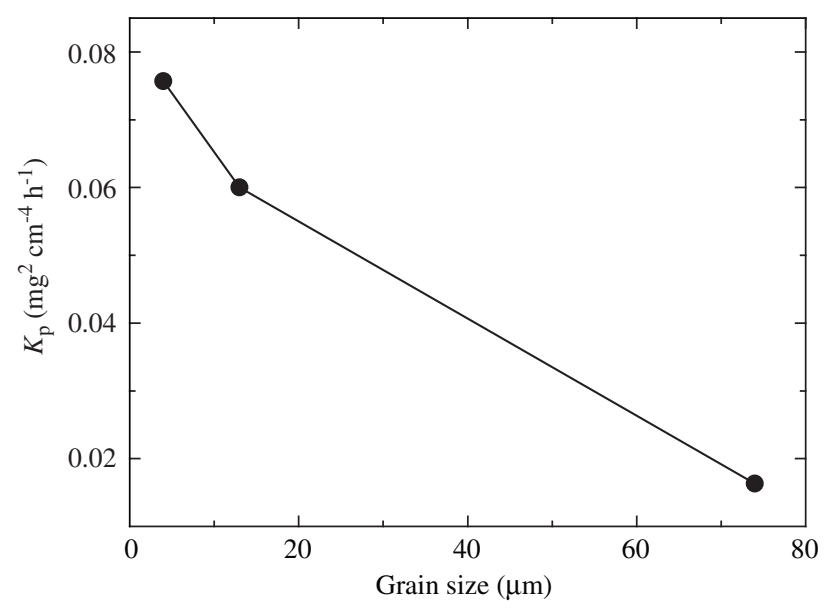

(a)

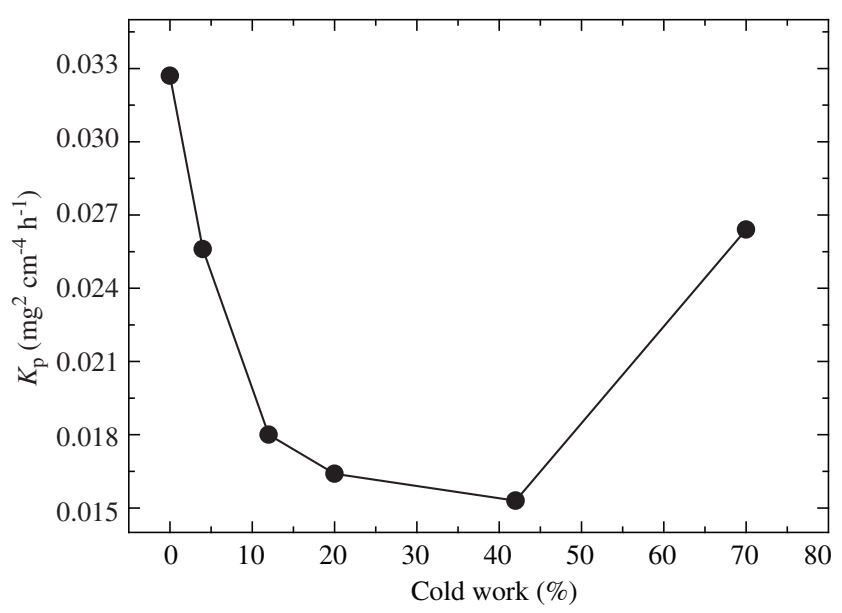

(b)

Figure 4. a) Effect of the grain size of the substrate on the oxidation kinetics of the $2.25 \mathrm{Cr} 1 \mathrm{Mo}$ oxidized at $550{ }^{\circ} \mathrm{C}$ in laboratory air for 72 hours; b) effect of the cold working on the oxidation kinetics of the $2.25 \mathrm{Cr} 1 \mathrm{Mo}$ oxidized in laboratory air at $550{ }^{\circ} \mathrm{C}$ for 24 hours.

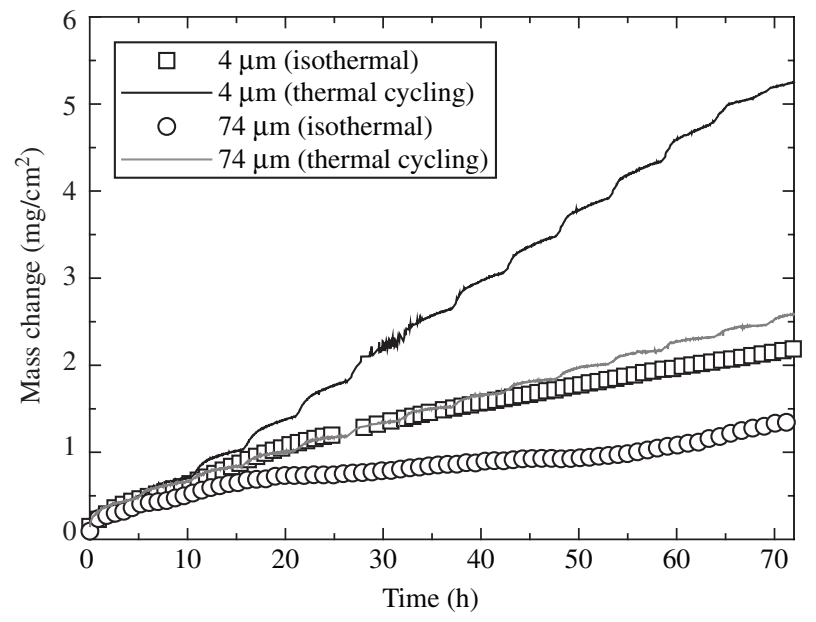

Figure 5. Oxidation of the steel $2.25 \mathrm{Cr} 1 \mathrm{Mo}$ with two different grain sizes at $550{ }^{\circ} \mathrm{C}$ in laboratory air under isothtermal and thermal cycling conditions.

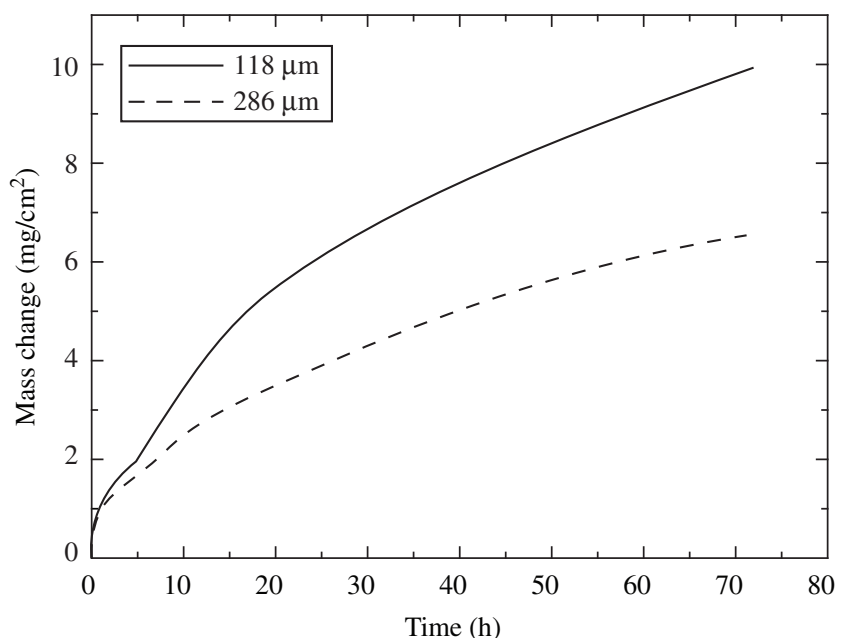

(a)

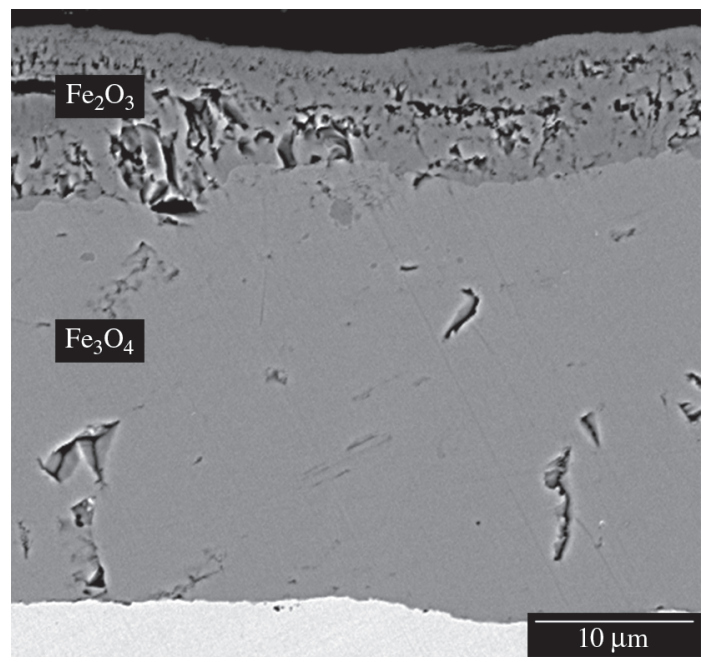

(b)

Figure 6. a) Mass change as a function of time for two grain sizes of pure iron at $550{ }^{\circ} \mathrm{C}$ for 72 hours; b) cross-section of the scale formed on the surface of pure iron at $550{ }^{\circ} \mathrm{C}$ for 72 hours. 
diffuse outwards due to the presence of pores leading to a decrease in the oxidation kinetics. When the specimen is cold worked, the extra dislocations in the metal inhibit the nucleation of pores by acting as vacancy sinks.

\section{Conclusions}

This study revealed that oxide scales grow outward as well as inward at $550{ }^{\circ} \mathrm{C}$ in pure iron and in the low-alloy ferritic steel 2.25Cr1Mo. An increased oxidation attack was observed when the grain size became smaller due to higher oxygen transport along substrate grain boundaries. The effect of cold working on the oxidation of the steel $2.25 \mathrm{Cr} 1 \mathrm{Mo}$ is different to that expected for pure iron, as observed by Caplan et al. ${ }^{17}$. The decrease in the oxidation kinetics for steel samples cold worked up to $42 \%$ can be explained by the higher $\mathrm{Cr}$ pipe diffusion leading to a higher $\mathrm{Cr}$-concentration within the inner oxide layer. This reduces the outward iron diffusion and the inward oxygen diffusion. For samples experienced cold working higher than $42 \%$, recrystallization took place causing a reduction in the dislocation density and very small new grain size. Therefore, high degrees of cold work accelerate oxidation kinetics of low-alloy steels. Thermal cycling increases strongly the oxidation kinetics of the steel $2.25 \mathrm{Cr} 1 \mathrm{Mo}$ due to the formation of cracks within the oxide scale during cooling.

\section{Acknowledgments}

This research has been supported by the EU project OPTICORR and by the Brazilian Research Foundation (CAPES) through a fellowship to one of the authors (V.B.Trindade).

\section{References}

1. Granaud G, Rapp RA. Thickness of the oxide layers formed during the oxidation of iron. Oxidation of Metals. 1977; 11:193-198.

2. Castle JE, Surman PL. The self-diffusion of oxygen in magnetite, techniques for sampling and isotopic analysis of micro quantities of water. The Journal of Physical Chemistry. 1967; 71:4255-4259.
3. Himmel L, Mehl RT, Birchenall CE. Self-diffusion of iron in iron oxides and the wagners theory of oxidation. Journal of Metals. 1953; 5:827-835.

4. Millot F. Niu Y. Diffusion of $\mathrm{O}^{18}$ in $\mathrm{Fe}_{3} \mathrm{O}_{4}$ : An experimental approach to study the behavior of minority defects in oxides. Journal of Physics and Chemistry of Solids. 1997; 58:63-72.

5. Reddy KPR, Cooper AR. Oxygen diffusion in $\mathrm{MgO}$ and $\alpha-\mathrm{Fe}_{2} \mathrm{O}_{3}$. Journal of the American Ceramic Society. 1983; 66:664-666.

6. Heumann T. Diffusion in Metallen. Springer-Verlag, Berlin, 1992.

7. Matsunaga S. Homma T. Influence on the Oxidation Kinetics of Metals by Control of Structure of Oxide Scales. Oxidation of Metals. 1976; 10:361-376.

8. Appannagaari N, Basu S. Modeling of O-18 tracer distribution during double oxidation - experiments for inward growing scales. Journal of Applied Physics. 1995; 78:2060-2069.

9. Wegener W, Borchardt G. Analysis of oxygen-18 tracer profiles in twostage oxidation experiments (I): predominant oxygen diffusion in the growing scale. Oxidation of Metals. 1991; 36:339-357.

10. Nakagawa K, Matsunaga Y, Yanagisawa T. Corrosion behavior of ferritic steels on the air sides of boiler tubes in a steam/air dual environment. Materials at High Temperatures. 2001; 18:51-56.

11. Bredesen R, Kofstad P. On the oxidation of iron in $\mathrm{CO}_{2}+\mathrm{CO}$ gas mixtures: I. Scale Morphology and Reaction Kinetics. Oxidation of Metals. 1990; 34:361-379.

12. Hussey RJ, Cohen M. The oxidation of $\mathrm{Fe}$ in the temperature range 450$550{ }^{\circ} \mathrm{C}$-II. The pressure range $10^{-3}-760$ Torr. Corrosion Science. 1971 11:713-721.

13. Chen RY, Yuen WY. Oxidation of low-carbon, low-silicon mild steel at $450-900{ }^{\circ} \mathrm{C}$ under conditions relevant to hot-strip processing. Oxidation of Metals. 2002; 57:53-79.

14. Smeltzer WW. The kinetics of wustite scale formation on iron. Acta Metallurgica. 1960; 8:377-383.

15. Kaur I, Gust W. Fundamentals of Grain and Interphase Boundary Diffusion. Ziegler Press, Stuttgart, 1988.

16. Töpfer J, Aggarwal S, Dieckmann R. Point defects and cation tracer diffusion in $\left(\mathrm{Cr}_{x} \mathrm{Fe}_{1-\mathrm{x}}\right)_{3-\delta} \mathrm{O}_{4}$ spinels. Solid State Ionics. 1995; 81:251-266.

17. Caplan D, Cohen M. Effect of cold work on the oxidation of iron from 400-650 ${ }^{\circ}$ C. Corrosion Science. 1966; 6:321-335. 